\title{
PRIMARY BREAST TUBERCULOSIS; MIMICKING DIAGNOSIS OF BREAST LUMP
}

Shabana Sultan, Shabeeh Nasar, Anant Rokhande

1. Assistant Professor. Department of Obstetrics \& Gynaecology, Gandhi Medical College, Bhopal

2. Associate Professor. Department of Surgery, People's Medical College, Bhopal.

3. Associate Professor. Department of Surgery, People's Medical College, Bhopal.

\section{CORRESPONDING AUTHOR:}

Dr. Shabana Sultan

House no 1/115, OPD block,

Doctors campus, Sultania lady hospital,

Bhopal, 462001, M. P.

E-mail: shaby_2k2@yahoo.com

Ph: 00919893192593.

ABSTRACT: Primary breast tuberculosis is a very rarely thought entity with most common clinical presentation as a breast lump. The significance of primary breast tuberculosis is due to its occurrence and under diagnosis as fibro adenoma, fibroadenosis, breast carcinoma and pyogenic breast abscess. So, breast tuberculosis can be a strongest differential diagnosis for patient presenting with lump. The disease is eminently curable with surgery and anti-tubercular chemotherapeutic agents, provided diagnosed in time.

KEY WORDS: Breast, tuberculosis, clinical presentation, diagnosis, management

INTRODUCTION: Primary tuberculosis (TB) of the breast is very rare even in developing countries where pulmonary and other forms of extra pulmonary manifestations of TB are endemic [1]. The incidence of isolated TB of the breast remains very low, ranging from $0.10 \%$ to $0.52 \%$.The disease usually affects women aged from 20 to 50 years [2].This article reports an otherwise healthy woman with primary TB of the breast, who presented with a breast lump for one year and histopathology reports were suggestive of breast TB.

CASE REPORT: A 30 year old married women, Para 2, presented with complaint of lump in right breast for one year. There was no past and family history of tuberculosis. On examination, lump was $6 \times 5 \mathrm{~cm}$, mobile, mild tender, firm, ill-defined at lower inner quadrant of right breast. There were multiple, matted, non tender lymph nodes in right axilla. On investigation, she had normal white blood cell count with lymphocyte predominance and normal ESR. Mantoux test was positive. Chest radiograph was normal. FNAC was suggestive of granulomatous inflammatory lesion. Gram staining was negative. Excision biopsy was done; operative findings were, a lump, $6.5 \times 5 \mathrm{~cm}$, ill-defined, mobile, and firm to hard at lower inner quadrant of right breast. Histopathology report showed few epithelioid granulomas with Langerhans giant cells and collar of lymphocytes, suggestive of granulomatous lesion suggesting tuberculosis of right breast (figure 1). Patient was started on anti-tubercular therapy of isoniazid $300 \mathrm{mg}$, rifampicin $600 \mathrm{mg}$, pyrazinamide $1500 \mathrm{mg}$ \& pyridoxine $10 \mathrm{mg}$ for 6 months post-operatively. Patient is well after anti-tubercular treatment. No recurrence was noticed after treatment in two year followup.

DISCUSSION: Breast tuberculosis is a rare form of tuberculosis [3]. Primary and secondary forms of the disease have been described. Primary disease refers to there being only one site of 
involvement in women who are not immunocompromised [2]. Breast tuberculosis commonly affects women in their reproductive age group [4]. The highest incidence of pulmonary tuberculosis reported between 21-30 age groups of females [5]. Breast tuberculosis most commonly presents as a lump [6]. Extra pulmonary tuberculosis occurring in the breast is extremely rare.

Breast tuberculosis is uncommon even in countries where the incidence of pulmonary and extra pulmonary tuberculosis is high. It is often mistaken for fibroadenosis, carcinoma and pyogenic breast abscess [3].Diagnosis is based on the identification of typical histological features [7]. Demonstration of caseating granulomas from the breast tissue and involved lymph nodes is usually sufficient for the diagnosis. Radiological imaging modalities like mammography or ultrasonography are unreliable in distinguishing it from carcinoma because of the variable pattern of presentation [8]. The disease is eminently curable with surgery and antitubercular chemotherapeutic drugs. Recurrence usually not occur after pooper excision and anti tubercular treatment ${ }^{7}$

CONCLUSION: Extra pulmonary tuberculosis occurring in the breast is extremely rare. Breast tuberculosis is uncommon even in countries where the incidence of pulmonary and extra pulmonary tuberculosis is high. In the absence of well-defined clinical features, the true nature of the disease remains obscure and it is often mistaken for carcinoma or benign breast disease. Caseating epithelioid cell granulomas in the tissue samples are diagnostic of tuberculosis. The disease is curable with surgery and anti-tubercular chemotherapeutic drugs.

\section{REFERENCES:}

1. Alagaratnam TT, Ong GB.Tuberculosis of the breast.Br J Surg 1980; 67:125-126.

2. Hale JA, Peters GN, Cheek JH: Tuberculosis of the breast: rare but still existent. Review of the literature and report of an additional case. Am J Surg 1985; 150:620-624.

3. 3.Kalac N, Ozkan B, Bayiz H, Dursun AB, Demirag F. Breast tuberculosis. Breast 2002; 11: 346-9.

4. Shinde SR, Chandawarkar RY, Deshmukh SP. Tuberculosis of the breast masquerading as carcinoma: a study of 100 patients. World J Surg 1995; 19: 379-81.

5. Shukla HS, Kumar S. Benign breast disorders in nonwestern populations: Part II - Benign breast disorders in India. World J Surg 1989; 13: 746-9

6. Gupta R, Gupta AS, Duggal N. Tubercular Mastitis. IntSurg 1982; 67: 422-4.

7. MallikaTewari\& H.S. Shukla. Department of Surgical Oncology, Institute of Medical Sciences, Banaras Hindu University, Varanasi, India. Indian J Med Res. August 2005; 122: 103-18.

8. Khanna R, Prasanna GV, Gupta P et al. Mammary tuberculosis: report on 52 cases. Postgrad Med J 2002; 78:4224 


\section{CASE REPORT}

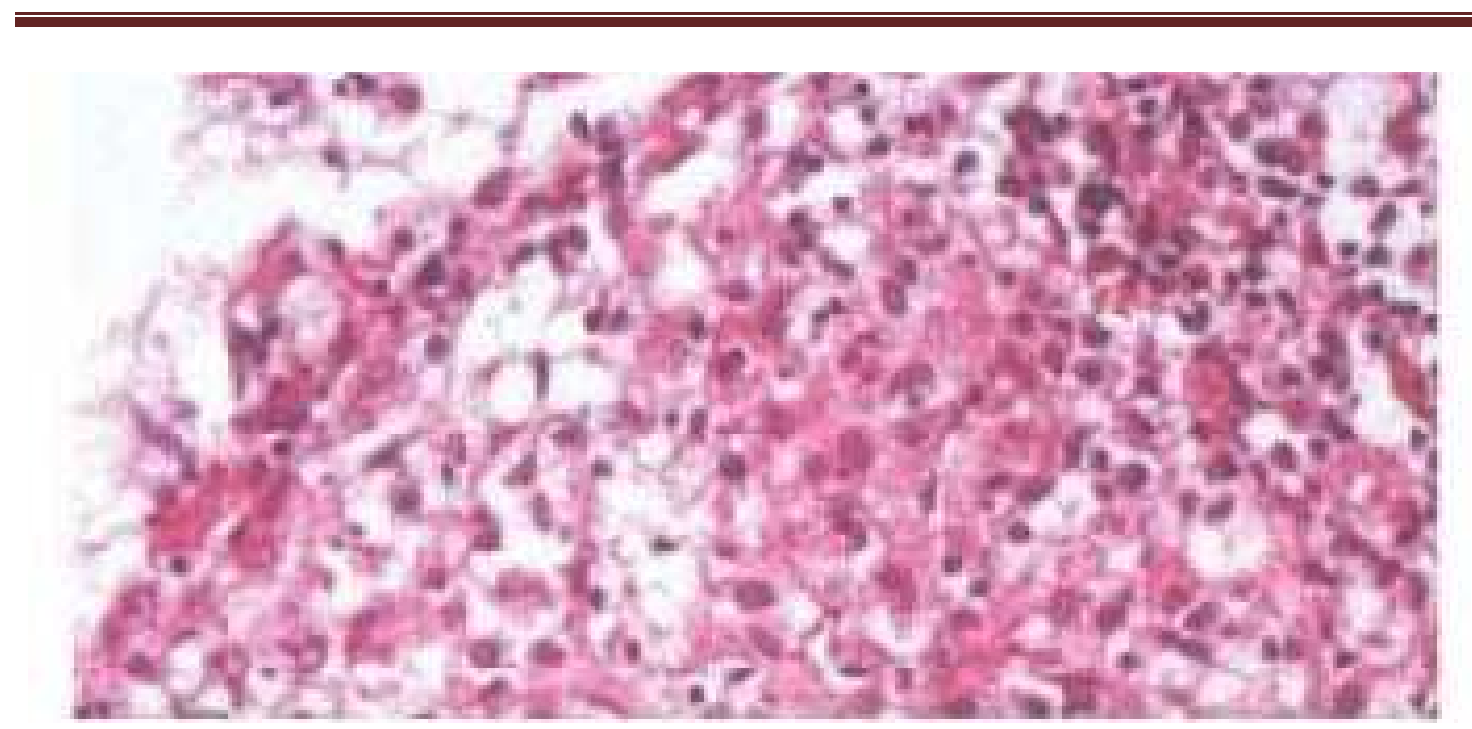

Figure-1, Breast Histopathology report shows few epithelioid granulomas with Langerhans giant cells and collar of lymphocytes 